\title{
DECISION SUPPORT SYSTEM FOR RISK MANAGEMENT IN AQUATIC PRODUCTS EXPORT TRADE, CHINA
}

\author{
Feng Wang ${ }^{1,2}$, Xiaoshuan Zhang ${ }^{1,2, *}$, Cheng Tan ${ }^{1,2}$, Chuanli Zhuang ${ }^{1,2}$, \\ Zetian $\mathrm{Fu}^{1,2, *}$ \\ ${ }^{1}$ China Agricultural University, Beijing, P. R. China, 100083 \\ ${ }^{2}$ Key Laboratory for Modern Precision Agriculture System Integration, Ministry of \\ Education, P. R. China, China Agricultural University, Beijing, P. R. China, 100083 \\ * Corresponding author, Address: China Agricultural University (east) 209\#, 100083
}

\begin{abstract}
The fishing industry not only acts as foreign exchange earner but also plays an important role in China's economy. But with the development of technology and liberalization of international trade, the foreign countries adopted in succession trade barriers to limit China's fishery product export, which had make China's fishery product export disproportionated with fishery products production. By the literature analysis, we find practical research aiming at aquatic products export trade is in shortage greatly. So it is necessary to provide risk management for export trade of aquatic products. A decision support system for risk management in aquatic products export trade had been developed by China Agricultural University. Based on questionnaire and interviews, we analyze the decision problems, user needs and the difficulties involved in developing the aquatic products risk management system. The system architecture and its components, such as database, knowledge base and model base are described. At last we discussed on problems we had encountered during development and promotion.
\end{abstract}

Keywords: aquatic products, export trade, decision support system, risk management, China

Wang, F., Zhang, X., Tan, C., Zhuang, C. and Fu, Z., 2008, in IFIP International Federation for Information Processing, Volume 258; Computer and Computing Technologies in Agriculture, Vol. 1; Daoliang Li; (Boston: Springer), pp. 371-378. 


\section{INTRODUCTION}

In China, aquaculture has been the fastest growing subsector within the agricultural economy, and the fishing industry not only acts as foreign exchange earner but also plays an important role in the China's economy by creating significant employment opportunities in various sectors of the seafood industry (Shekar Bose et al., 2005). China had exceeded over the Thailand in volume and been the world's largest exporter of aquatic products since 2002, and average export volume has increased 17\% (Zhang Xiaoshuan, 2005). The export value is now around $\$ 9.36$ billion at 2006, up $18.7 \%$, and ranks first in bulk agricultural exports all the same.

However, with such tremendous growth in the export volume of aquatic products and the globalization of fish trade, the new problems are emerging. Many foreign countries have tightened food safety controls, imposed additional costs and requirements on imports, and adopted technology barrier to limit China's fishery product export (Zhou Deqing et al., 2003; Lahsen Ababouch, 2006). Secondly, the international market for fish and seafood products is dynamic greatly in nature due to some factors (Shekar Bose et al., 2005). Moreover, China's aquatic products export market is excessively concentrated in Japan, Korea, EU and US. When those countries adopt new trade policy, the export trade of aquatic products will be severely influenced. All these risk contributed to the instability and restrained from exerting advantage of China's aquatic products export trade.

Recent theoretical literature had provided some useful information concerning some of above mentioned problems. The cases and theoretical analysis, which focus on analysis on influence extent, internal and exterior reasons of trade friction, and the market conditions when the cases occur (Lahsen Ababouch, 2000; Zhang Fan, 2006; Chen Li, 2005; Yu Yahong, 2006; Meng Di et al., 2006; Titus O. Awokuse, 2006). Moreover, there are many literatures about fishery forecasting model and information system, which are powerful and useful to support participants of aquaculture industry to predict market risk and related information (Max Nielsen, 2000; Zhang Xiaoshuan, 2004; Helmut Herwartz, 2005).

It can be found that the practical research on risk management of aquatic products export trade is almost inexistent. So it is necessary to provide a useful risk management tool for aquatic products export trade. A decision support system (DSS) for export trade risk management can be typically used to detect any change in international aquatic products market via integration of market segmentation, risk early warning and forecasting, and offer ways to automate decision-making by generating information immediately accessible to all actors in a straightforward way.

Based on the above analysis, this paper introduces and discusses the experience in developing DSS-RMAPET, a decision support system for risk 
management in aquatic products export trade by China Agricultural University. The following is organized as: section 2 describes the users' need analysis; Section 3 and 4 show the system design and implementation. Then the last section draws some conclusions and further improvement.

\section{THE SURVEY AND USERS' NEED ANALYSIS}

\subsection{The decision-makers and decisions}

Table 1 identifies the decision problems that the different decision-makers need to face by analyzing the results of questionnaires and interviews based on aquatic products export trade.

Table 1. Decision-makers and decisions

Government at national, provincial, County level, who need evaluate product prices, production, trade and macroeconomic aggregate by species and quality of fish to

- $\quad$ Early-warning risk by trade protectionism (anti-dumping, TBT, and so on.) to avoid potential dumping and protect healthy development of fishery sector.

- Set out an enabling policy and regulatory environment at national and international levels with clearly rules and standards.

- $\quad$ Establishing appropriate food control systems and programmes at national and local levels.

- Collect information about the new aquaculture management and development policies, economical direction, rules and laws of import country, which play an important role in risk prevention.

Export enterprises of aquatic products and some organizations (including fishery institution), who give service to aquaculture production enterprises and farmers to

- Understand the objective reasons and conditions bringing about trade risk, which are gathered for accounting, statistics and forecasting the future potential risk.

- $\quad$ Establish the factors which influence the international fish products market, and select appropriate time entrance to target market.

- Sum up and classify results and losses caused by export trade risk, such as exchange rate, anti-dump law, TBT etc.

- $\quad$ Seek how to shift the pertinent risk to the other memberships.

\subsection{The needs for DSS-RMAPET}

Table 2 illustrates the key function modules after analyzing the results of questionnaires and interviews based on aquatic products export trade. 
Table 2. Modules and their functions

\begin{tabular}{ll}
\hline Module & Function \\
\hline Data management module & $\begin{array}{l}\text { Responsible for collecting data involved in import } \\
\text { country's economical condition, trade policy, trade risk } \\
\text { cases and so on, and analyzing and preparing the data } \\
\text { sets for market classification, forecasting and early }\end{array}$ \\
warning. & $\begin{array}{l}\text { Assessing all import countries enables effective } \\
\text { comparison, then selecting reasonable export markets. }\end{array}$ \\
Market classification module & $\begin{array}{l}\text { Responsible for monitoring and forecasting the export } \\
\text { volume of aquatic products with relevant analysis. }\end{array}$ \\
Rorecasting module & $\begin{array}{l}\text { Evaluating the degrees of trade risk and issue a warning } \\
\text { signal. }\end{array}$ \\
\hline
\end{tabular}

\section{SYSTEM DESIGN}

\subsection{Database module}

The module is with responsibility for preparing the data sets for the model base and knowledge base needed for export trade risk management. It is composed of a database management system (DBMS) and a series of minidatabases. The DBMS provides all required data management capabilities including commands for adding, deleting, updating, browsing, and sorting records as well as importing and exporting (Omar F, 2000). The database is composed of three sections, including: Macro-economy information; Trade barriers information; Trade policy, rules and regulations of aquatic products safety and quality, such as import protection, new safety regulations and standards of import country, etc.

\subsection{Knowledge base module}

The knowledge base contains both factual and heuristic knowledge. Factual knowledge is that knowledge of the task domain that is widely shared, typically found in textbooks or journals, and commonly agreed upon by those knowledgeable in the particular field. Heuristic knowledge is the less rigorous, more experiential, more judgmental knowledge of performance, which is the knowledge of good practice, good judgment, and plausible reasoning in the field.

In the research, the objective of developing a knowledge base is to provide expert interpretation of available data regarding trade risk, which have an important impact on China's aquatic products export. Therefore, the knowledge base stores abundant knowledge including the forms of 
international aquatic product market classification, the cases of trade risks, relative risk forecasting and early warning result, an indication of the relative possibility in the accuracy of that result, and the preventive measure, as well as some advice for decision-making.

\subsection{Model base module}

The model base is the core component of this system, which operates a series of models to provide the managers with important risk decision reference.

1) The international market classification model

In order to avoid relying on these markets excessively and improve the ability to resist aquatic products market risks, it is necessary to develop and exploit new markets and reduce make market concentration degree. So the classification and selection of international aquatic products market are the first and most important step in export strategy.

Factors impacting international aquatic products market are fuzzy, uncertain and complicated. A neuro-fuzzy system, which can combine neural networks and fuzzy logic, and provide the advantage of reducing training time. Moreover, such results emphasize the benefits of the fusion of fuzzy and neural network technologies as it facilitates an accurate initialization of the network in terms of the parameters of the fuzzy reasoning system (Muhammad Aqil et al., 2007). Therefore, the Fuzzy Artificial Neural Network Inference System (FANNIS) classification model is established, which can offer the comparatively accurate division of the international aquatic products market and reduce aquatic products export market risk effectively.

FANNIS is not a fixed inference system in advance. It needs to learn according to the regulations which experts have established, then forms a network that can classify international aquatic products market. So there are two processes to ensure reasonable classification for international aquatic products market: learning and classification.

2) The export volume forecasting model

In recent years, China's export volume of aquatic products show growing trend, but the strict trade barriers of foreign country are increasing rapidly, which will have a profound impact on export volume of aquatic products. It is a perceivable need to develop forecasting models able to capture export volume changes.

Considering that all the raw sequences about export trade are vibrating and changing in a certain variety trend. To improve the predication capability, the research introduced $\operatorname{Markov}(1,1)-\mathrm{GM}$ model by integrating the Markov chain with the $\operatorname{GM}(1,1)$, which can forecast the future by 
analyzing the inside regulation of development in time to come, and it reflects the influence degree and laws. The $\operatorname{GM}(1,1)$-Markov model, i.e. a single variable first order grey model integrated with Markov Chain.

\section{3) The trade risk early-warning model}

The model is responsible for integrating information and operational experience of experts with forecasting results to evaluate the degrees of trade risk and issue a warning signal. When the warning situations emerge, the system need to analyze and evaluate the creditability and impact degree on export trade of aquatic products with domain experts, then provide effective decision advice on dealing with, avoiding and breaking through. According to the procedure of early-warning system proposed by Fulai Huang (2005), the early-warning process include searching the origin/source that warning condition is produced, choosing warning signs, determining warning limits of the warning signs, computing the early-warning index, compartmentalizing warning grade and determining warning degree. In this paper, the early-warning model for export trade risk is developed based on Support Vector Machines (SVM).

\section{SYSTEM IMPLEMENTATION}

The fishery market data are constantly being updated and the mathematical models are also potentially changeable. So a B/S/S, i.e. threetier architecture, was adopted as our system's fundamental architecture to provide the transparency among the data layer, business logic layer and the user interface layer.

There are many solutions for developing the web-based systems. The solution, which is Microsoft .NET Framework 1.1+ASP.NET+MS SQL Server $2000+$ IIS $6.0+\mathrm{COM}$, is adopted to develop this system. Among the development plan:

- Microsoft's Visual Basic .NET is one of the core development languages in the new Visual Studio .NET and it remains a critical component in almost every enterprise wide development effort. It is serving as the main develop language to bridge user interface and web server and database server.

- MS SQL Server 2000, a relational database management system and data warehouse development tool, is serving as the back-end of the workstation to facilitate data storage and retrieval and as a means to preserve analysis methodologies and knowledge.

- IIS 6.0 is serving as a web server to provide information service. 
- Microsoft COM technology enables software components to communicate. COM is used to create re-usable software components, link components together to build applications, and take advantage of Windows services.

\section{CONCLUSION AND DISCUSSION}

From the above analysis, the main outcomes can be outlined as follows:

- Different software modules for data storage, communication, processing, early warning and evaluation as well as forecasting have been successfully developed and combined into DSS-RMAPET software package. We also integrated fuzzy logic, ANN and grey theory to produce a hybrid intelligent algorithm for solving evaluation, forecast and early warning models. The integration has enhanced the system performance. Results of this study have important implications for the refinement of aquatic products risk assessment model and optimization of aquatic products export trade configuration.

- The system provides a comprehensive decision support for users due that it integrates multiple knowledge including macro-economic theory, trade policy, forecasting and early-warning methods and so on.

- By utilizing crossing validation to select anova as the kernel function, indicators of warning situation and warning omen as variables, an earlywarning model based on support vector machine is established to study the export trade risk of aquatic products.

- Based on the theory of fuzzy inference system, the author establishes an FANNIS classified model of international aquatic product market by introducing the artificial neural network as fuzzy inference device and nonfuzzy device. This classified model has simplified the procedure structured by fuzzy inference system. It can offer the comparatively accurate division of the international aquatic products market.

- An effective DSS-RMAPET depends on both the model and data. The availability and accuracy of data are major constraints to the usefulness of such models. In China, the fishery market data are scattered among a multitude of producers with dissimilar formats, resolutions. Moreover, it is difficult to acquire relevant trade data about import countries, and new trade risk cases and fish trade policy need to be tracked timely, so the update of track record of system models for risk management is not so good.

- Further research is to integrate more effective forecasting and early warning method into the system to improve the system's intelligent functions, for example, Knowledge Discovery in Database (KDD) can be used to produce the rules automatically for the knowledge base embedded in the DSS. 


\title{
ACKNOWLEDGEMENTS
}

\author{
This study has been funded by the EU FP6 program (FP6-016333-2).
}

\section{REFERENCES}

Chen Li. Risk assessment and international aquatic products trade. Journal of Fujian Fisheries, 2005, 2: 55-56 (in Chinese)

Fulai Huang and Feng Wang. A system for early-warning and forecasting of real estate development. Automation in Construction, Volume 14, Issue 3, June 2005, 333-342

Helmut Herwartz and Henning Weber. Exchange rate uncertainty and trade growth - a comparison of linear and non-linear (forecasting) models Applied Stochastic Models in Business and Industry, 2005, 21: 1-26

http://www.statsoft.com. Support Vector Machines (SVM)

K. Bryant. ALEES: An agricultural loan evaluation expert system. Expert system with application 2001, 21: 75-85

La Sen, Liu Yadan. Risk analysis and international aquatic products trade. Chinese Fisheries Economy Research, 2004, 4: 33-34 (in Chinese)

Lahsen Ababouch. Assuring fish safety and quality in international fish trade. Marine Pollution Bulletin, 2006, 53: 561-568

Lahsen Ababouch. The role of government agencies in assessing HACCP. Food Control, 2000, 11: 137-142

Max Nielsen. Forecast of Danish ex-vessel seafood prices. Http://esb.sdu.sk/ uho/ime/ EAFE2000/papers/maxniel.pdf

Meng Di, Zhou Deqing. Review on Risk Analysis of Seafood. Journal of Chinese Institute of Food Science and Technology, 2006, 1: 390-395 (in Chinese)

Muhammad Aqil, Ichiro Kita, Akira Yano and Soichi Nishiyama. A comparative study of artificial neural networks and neuro-fuzzy in continuous modeling of the daily and hourly behaviour of runoff. Journal of Hydrology, 2007, 337: 22-34

Omar F. El-Gayar. ADDSS: a tool for regional aquaculture development, Aquacultural Engineering, 2000, 23: 181-202

Shekar Bose, Arna Galvan. Export supply of New Zealand's live rock lobster to Japan: an empirical analysis. Japan and the World Economy, 2005, 17: 111-123

Titus O. Awokuse, Yan Yuan. The Impact of Exchange Rate Volatility on U.S. Poultry Exports. Agribusiness, 2006, 22: 233-245

$\mathrm{Yu}$ Yahong. Some reflections on aquatic products safety of Chinese export trade. China Fisheries, 2006, 1: 16-18 (in Chinese)

Zhang Xiaoshuan, Hu Tao, Brain Revell and Fu Zetian. A forecasting support system for aquatic products price in China. Expert Systems with Applications, 2005, 28: 119-126

Zhang Xiaoshuan, Zhang Jian, Fu Zetian. A forecasting support system for aquatic products price based agent. Computer engineering, 2004, 8: 65-67

Zhou Deqing, Li Xiaochuan. The quality safety and its promotion of fishery product in China. Fishery modernization, 2003, 1: 3-5 (in Chinese) 